\title{
Convergence of a Hybrid Iterative Scheme for Fixed Points of Nonexpansive Maps, Solutions of Equilibrium, and Variational Inequalities Problems
}

\begin{abstract}
Bashir Ali
Department of Mathematical Sciences, Bayero University, P.M.B. 3011, Kano, Nigeria

Correspondence should be addressed to Bashir Ali; bashiralik@yahoo.com

Received 26 November 2012; Accepted 30 January 2013

Academic Editor: Liwei Zhang

Copyright (C) 2013 Bashir Ali. This is an open access article distributed under the Creative Commons Attribution License, which permits unrestricted use, distribution, and reproduction in any medium, provided the original work is properly cited.

Let $K$ be a closed, convex, and nonempty subset of a real $q$-uniformly smooth Banach space $E$, which is also uniformly convex. For some $\kappa>0$, let $T_{i}: K \rightarrow E i \in \mathbb{N}$ and $A: K \rightarrow E$ be family of nonexpansive maps and $\kappa$-inverse strongly accretive map, respectively. Let $G: K \times K \rightarrow \mathbb{R}$ be a bifunction satisfying some conditions. Let $P_{K}$ be a nonexpansive projection of $E$ onto $K$. For some fixed real numbers $\delta \in(0,1), \lambda \in\left(0,\left(q \kappa / d_{q}\right)^{1 /(q-1)}\right)$, and arbitrary but fixed vectors $x_{1}, u \in E$, let $\left\{x_{n}\right\}$ and $\left\{y_{n}\right\}$ be sequences generated by $G\left(y_{n}, \eta\right)+(1 / r)\left\langle\eta-y_{n}, j_{q}\left(y_{n}-x_{n}\right)\right\rangle \geq 0, \forall \eta \in K, x_{n+1}=\alpha_{n} u+(1-\delta)\left(1-\alpha_{n}\right) x_{n}+\delta \sum_{i \geq 1} \sigma_{i n} T_{i} P_{K}\left(y_{n}-\lambda A y_{n}\right), n \geq 1$, where $r \in(0,1)$ is fixed, and $\left\{\alpha_{n}\right\},\left\{\sigma_{i, n}\right\} \subset(0,1)$ are sequences satisfying appropriate conditions. If $F:=\left[\cap_{i=1}^{\infty} F\left(T_{i}\right)\right] \cap \operatorname{VI}(K, A) \cap \mathrm{EP}(G) \neq \emptyset$, under some mild conditions, we prove that the sequences $\left\{x_{n}\right\}$ and $\left\{y_{n}\right\}$ converge strongly to some element in $F$.
\end{abstract}

\section{Introduction}

Let $E$ be a real normed space and $E^{*}$ its dual space. For some real number $q(1<q<\infty)$, the generalized duality mapping $J_{q}: E \rightarrow 2^{E^{*}}$ is defined by

$$
J_{q}(x)=\left\{f^{*} \in E^{*}:\left\langle x, f^{*}\right\rangle=\|x\|^{q},\left\|f^{*}\right\|=\|x\|^{q-1}\right\},
$$

where $\langle\cdot, \cdot\rangle$ denotes the pairing between elements of $E$ and elements of $E^{*}$.

For $q=2, J_{2}$ usually denoted by $J$ is called the normalised duality mapping.

Let $E$ be a real Banach space; a map $A: D(A) \rightarrow E$ is said to be accretive if for all $x, y \in D(A)$, there exists $j_{q}(x-y) \in$ $J_{q}(x-y)$ such that

$$
\left\langle A x-A y, j_{q}(x-y)\right\rangle \geq 0 .
$$

For some real number $\kappa>0, A$ is called $\kappa$-inverse strongly accretive if for all $x, y \in D(A)$, there exists $j_{q}(x-y) \in J_{q}(x-y)$ such that

$$
\left\langle A x-A y, j_{q}(x-y)\right\rangle \geq \kappa\|A x-A y\|^{q} .
$$

Observe that a $\kappa$-inverse strongly accretive map is $1 / \kappa$ Lipschitzian.

Let $K$ be a nonempty, closed, and convex subset of $E$, and let $A: K \rightarrow E$ be an accretive mapping. A variational inequality problem is, searching for $x^{*} \in K$ such that for some $j_{q}\left(v-x^{*}\right) \in J_{q}\left(v-x^{*}\right)$

$$
\left\langle A x^{*}, j_{q}\left(v-x^{*}\right)\right\rangle \geq 0, \quad \forall v \in K .
$$

Let $G: K \times K \rightarrow \mathbb{R}$ be a bifunction on a closed convex nonempty subset $K$ of a real Banach space $E$; an equilibrium problem is searching for $x^{*} \in K$ such that

$$
G\left(x^{*}, v\right) \geq 0, \quad \forall v \in K \text {. }
$$

A set of solutions of the problems (4) and (5) are denoted by $\operatorname{VI}(K, A)$ and $\operatorname{EP}(G)$, respectively.

Let $P$ be a mapping of $E$ onto $K$. Then, $P$ is said to be sunny if $P(P x+t(x-P x))=P x$ for all $x \in E$ and $t \geq 0$. A mapping $P$ of $E$ into $E$ is said to be a retraction if $P^{2}=P$. If a mapping $P$ is a retraction, then $P z=z$ for every $z \in R(P)$, range of $P$. A subset $K$ is said to be sunny nonexpansive retract of $E$ if there exists a sunny nonexpansive retraction of $E$ onto 
$K$. A retraction $P$ is said to be orthogonal if for each $x, x-P(x)$ is normal to $K$ in the sense of James [1].

It is well known (see [2]) that if $E$ is a Banach space; a projection mapping is a sunny nonexpansive retraction $P$ of $E$ onto $K$. If $E$ is uniformly smooth and there exists a nonexpansive retraction of $E$ onto $K$, then there exists a nonexpansive projection of $E$ onto $K$. If $E$ is a real smooth Banach space, then $P$ is an orthogonal retraction of $E$ onto $K$ if and only if $P(x) \in K$ and $\left\langle P(x)-x, j_{q}(P(x)-y)\right\rangle \leq 0$ for all $y \in K$. It then follows that, for $x, y \in K$, we have $\langle P(x)-$ $\left.x, j_{q}(P(x)-P(y))\right\rangle \leq 0$ and $\left\langle P(y)-y, j_{q}(P(y)-P(x))\right\rangle \leq 0$ which implies

$$
\|P(x)-P(y)\|^{q} \leq\left\langle x-y, j_{q}(P(x)-P(y))\right\rangle .
$$

An accretive mapping $A$ is said to be maximal if its graph $\mathrm{GF}(A)$ is not contained in the graph of any other accretive map. Equivalently, $A$ is maximal accretive if for every $\left(v_{0}, w_{0}\right) \in E \times E$ such that $\left\langle w-w_{0}, j_{p}\left(v-v_{0}\right)\right\rangle \geq 0$ holds for all $w \in A v, v \in K$; then, $w_{0} \in A v_{0}$. A mapping $T$ with domain $D(T)$ and range $R(T)$ in $E$ is said to be demiclosed at $p$ if whenever $\left\{x_{n}\right\}$ is a sequence in $D(T)$ such that $x_{n} \rightarrow$ $x^{*} \in D(T)$ and $T x_{n} \rightarrow p$; then, $T x^{*}=p$. The following proposition is known to hold; see, for example, [3].

Proposition 1. Let $A: K \rightarrow E$ be a $\kappa$-inverse strongly accretive map. Let $M$ be defined by

$$
M v= \begin{cases}A v+N_{K} v, & v \in K, \\ \emptyset, & v \notin K,\end{cases}
$$

where $N_{K} v=\left\{w \in E:\left\langle w, j_{q}(v-u)\right\rangle \geq 0\right.$, for all $\left.u \in K\right\}$; then, $M$ is maximal accretive and $u \in M^{-1}(0)$ if and only if $u \in \mathrm{VI}(K, A)$.

Recently, Maingé [4] studied the Halpern-type scheme for approximation of a common fixed point of countable infinite family of nonexpansive mappings in a real Hilbert space.

The present author [3] proved a strong convergence theorem for family of nonexpansive maps and solution of variational inequality problems. Kumam and Jaiboon [5] studied a hybrid iterative method for mixed equilibrium problem and variational inequality problem in the framework of a real Hilbert space.

Various numerous authors studied the problem of approximating solutions of equilibrium and fixed point problems in the framework of a real Hilbert space; see, for example, [5-18] and the references contained therein. In [19], Ceng et al. studied this problem in the framework of a uniformly smooth and uniformly convex Banach space.

Takahashi and Zembayashi [20] (see also [21-23]) studied the problem of approximating solutions of equilibrium problems and fixed points of some nonlinear maps in the framework of real Banach spaces. It is our purpose in this paper to introduce a new hybrid iterative method for approximating a common element in the intersection of the set of fixed points of countable infinite family of nonexpansive mappings, the set of solutions of variational inequality problem, and the set of solutions of equilibrium problem in Banach spaces. Our theorems extend and improve some recent important results, and our method of proof in this paper is of independent interest.

\section{Preliminaries}

Let $S:=\{x \in E:\|x\|=1\}$ denote a unit sphere of the real Banach space E. $E$ is said to have a Gâteaux differentiable norm if the limit

$$
\lim _{t \rightarrow 0} \frac{\|x+t y\|-\|x\|}{t}
$$

exists for each $x, y \in S$; E is said to have a uniformly Gâteaux differentiable norm if for each $y \in S$, the limit is attained uniformly for $x \in S$. Let $E$ be a normed space with $\operatorname{dim} E \geq 2$. The modulus of smoothness of $E$ is the function $\rho_{E}:[0, \infty) \rightarrow$ $[0, \infty)$ defined by

$$
\rho_{E}(\tau):=\sup \left\{\frac{\|x+y\|+\|x-y\|}{2}-1:\|x\|=1 ;\|y\|=\tau\right\} .
$$

The space $E$ is called uniformly smooth if and only if $\lim _{t \rightarrow 0^{+}}\left(\rho_{E}(t) / t\right)=0$. For some constant $q>1, E$ is called $q$-uniformly smooth if there exists a constant $c>0$ such that $\rho_{E}(t) \leq c t^{q}, t>0$.

The modulus of convexity of $E$ is the function $\delta_{E}$ : $(0,2] \rightarrow[0,1]$ defined by

$$
\delta_{E}(\epsilon)=\inf \left\{1-\left\|\frac{x+y}{2}\right\|:\|x\|=\|y\|=1, \epsilon=\|x-y\|\right\} .
$$

$E$ is called uniformly convex if and only if $\delta_{E}(\epsilon)>0$ for all $\epsilon \in(0,2]$.

A Banach space $E$ is said to be strictly convex if $\|x-y\| / 2<$ 1 for $x, y \in E$ with $\|x\|=1=\|y\|$ and $x \neq y$.

It is well known that if $E$ is smooth then the duality mapping is singled valued, and if $E$ has uniformly Gâteaux differentiable norm then the duality mapping is norm-toweak $^{*}$ uniformly continuous on bounded subset of $E$. Also, every $q$-uniformly smooth space is uniformly smooth and has a uniformly Gâteaux differentiable norm, and every uniformly convex space is strictly convex.

In the sequel, we will make use of the following results.

Lemma 2 (see Petryshyn [24]). Let E be a real normed linear space. Then, the following inequality holds:

$$
\begin{gathered}
\|x+y\|^{2} \leq\|x\|^{2}+2\langle y, j(x+y)\rangle \\
\forall x, y \in E, j(x+y) \in J(x+y) .
\end{gathered}
$$

Theorem 3 (see Goebel and Kirk [25]). Let E be a real uniformly convex Banach space, $K$ a closed convex subset of $E$, and $T: K \rightarrow E$ a nonexpansive mapping. Then, $(I-T)$ is demiclosed at zero, where I denotes the identity map.

Lemma 4 (see Suzuki [26]). Let $\left\{x_{n}\right\}$ and $\left\{y_{n}\right\}$ be bounded sequences in a Banach space $E$, and let $\left\{\beta_{n}\right\}$ be a sequence 
in $[0,1]$ with $0<\liminf \beta_{n} \leq \lim \sup \beta_{n}<1$. Suppose that $x_{n+1}=\beta_{n} y_{n}+\left(1-\beta_{n}\right) x_{n}$ for all integers $n \geq 0$ and $\lim \sup \left(\left\|y_{n+1}-y_{n}\right\|-\left\|x_{n+1}-x_{n}\right\|\right) \leq 0$. Then, $\lim \left\|y_{n}-x_{n}\right\|=0$.

Lemma 5 (see Xu [27]). Let $\left\{a_{n}\right\}$ be a sequence of nonnegative real numbers satisfying the following relation:

$$
a_{n+1} \leq\left(1-\alpha_{n}\right) a_{n}+\alpha_{n} \sigma_{n}+\gamma_{n}, \quad n \geq 0,
$$

where (i) $\left\{\alpha_{n}\right\} \subset[0,1], \sum \alpha_{n}=\infty$; (ii) $\lim \sup \sigma_{n} \leq 0$; (iii) $\gamma_{n} \geq 0$; $(n \geq 0), \sum \gamma_{n}<\infty$. Then, $a_{n} \rightarrow 0$ as $n \rightarrow \infty$.

Lemma 6 (see Xu [28]). Let E be a real q-uniformly smooth Banach space for some $q>1$; then, there exists some positive constant $d_{q}$ such that

$$
\|x+y\|^{q} \leq\|x\|^{q}+q\left\langle y, j_{q}(x)\right\rangle+d_{q}\|y\|^{q}
$$

for all $x, y \in E$ and $j_{q}(x) \in J_{q}(x)$.

Lemma 7 (see Kamimura and Takahashi [29]). Let E be a real smooth and uniformly convex Banach space, and let $R>0$. Then, there exists a strictly increasing, continuous, and convex function $g:[0,2 R] \rightarrow \mathbb{R}$ such that $g(0)=0$ and $g(\|x-y\|) \leq$ $\|x\|^{2}-2\langle x, j y\rangle+\|y\|^{2}$ for all $x, y \in B_{R}$.

The following conditions are required on the bifunction $G: K \times K \rightarrow \mathbb{R}$ for solving equilibrium problems with respect to $G$ :

(A1) $G(x, x)=0$ for all $x \in K$;

(A2) $G$ is monotone; that is, $G(x, y)+G(y, x) \leq 0$ for all $x, y \in K$

(A3) for all $x, y, z \in K, \lim \sup _{t \rightarrow 0^{+}} G(t z+(1-t) x, y) \leq$ $G(x, y)$;

(A4) for all $x \in K, G(x, \cdot)$ is convex and lower semicontinuous.

Lemma 8 (see Blum and Oettli [30]). Let $E$ be a real smooth, strictly convex, and reflexive Banach space. Let $G: K \times K \rightarrow \mathbb{R}$ be a bifunction satisfying (A1)-(A4), and let $x \in E, r>0$. Then, there exists $z \in K$ such that

$$
G(z, y)+\frac{1}{r}\langle y-z, j(z-x)\rangle \geq 0, \quad \forall y \in K .
$$

Lemma 9. Let $K$ be a closed convex nonempty subset of a real uniformly smooth and strictly convex Banach space E. Let $G$ : $K \times K \rightarrow \mathbb{R}$ be a bifunction satisfying (A1)-(A4). For $r>0$ and $x \in E$, define a map $T_{r}: E \rightarrow K$ by

$$
\begin{aligned}
T_{r} x=\{z & \in K: G(z, y) \\
& \left.+\frac{1}{r}\langle y-z, j(z-x)\rangle \geq 0, \forall y \in K\right\} .
\end{aligned}
$$

Then, the following hold:

(i) $T_{r}$ is single-valued;

(ii) $\operatorname{Fix}\left(T_{r}\right)=E P(G)$; (iii) if $T_{r}$ is firmly nonexpansive-type, that is, for $x, y \in E$,

$$
\left\langle T_{r} x-T_{r} y, j\left(T_{r} x-T_{r} y\right)\right\rangle \leq\left\langle x-y, j\left(T_{r} x-T_{r} y\right)\right\rangle,
$$

then $\operatorname{EP}(G)$ is closed and convex.

Proof. (i) Let $z_{1}, z_{2} \in T_{r}$, then

$$
\begin{aligned}
& G\left(z_{1}, z_{2}\right)+\frac{1}{r}\left\langle z_{2}-z_{1}, j\left(z_{1}-z_{2}\right)\right\rangle \geq 0, \\
& G\left(z_{2}, z_{1}\right)+\frac{1}{r}\left\langle z_{1}-z_{2}, j\left(z_{2}-z_{1}\right)\right\rangle \geq 0 .
\end{aligned}
$$

Adding these inequalities and using (A2), we get

$$
\left\langle z_{2}-z_{1}, j\left(z_{1}-z_{2}\right)\right\rangle \geq 0 \text {, }
$$

which implies $z_{1}=z_{2}$. Consider

(ii)

$$
\begin{aligned}
z \in F\left(T_{r}\right) & \Longleftrightarrow z=T_{r} z \\
& \Longleftrightarrow G(z, y)+\frac{1}{r}\langle y-z, j(z-z)\rangle \geq 0, \\
& \Longleftrightarrow G(z, y) \geq 0, \quad \forall y \in K, \\
& \Longleftrightarrow z \in E P(G) .
\end{aligned}
$$

(iii) $\mathrm{EP}(G)$ is closed and convex follows from (ii) and the fact that every firmly nonexpansive map is nonexpansive and the fixed point set of nonexpansive map is closed and convex.

Let $E$ be a real $q$-uniformly smooth Banach space, and for some $\lambda>0$, let $I: K \rightarrow K$ and $A: K \rightarrow E$ be the identity and $\kappa$-inverse strongly accretive mappings, respectively. Then, for the map $(I-\lambda A): K \rightarrow E$, we have the following estimates:

$$
\begin{aligned}
\|(I- & \lambda A) x-(I-\lambda A) y \|^{q} \\
= & \|x-y-\lambda(A x-A y)\|^{q} \\
\leq & \|x-y\|^{q}-q \lambda\langle A x-A y, j(x-y)\rangle \\
& +d_{q} \lambda^{q}\|A x-A y\|^{q} \\
\leq & \|x-y\|^{q}-\lambda\left(q \kappa-d_{q} \lambda^{q-1}\right)\|A x-A y\|^{q} .
\end{aligned}
$$

If $\lambda$ is chosen such that $0 \leq \lambda \leq\left(q \kappa / d_{q}\right)^{1 /(q-1)}$, we then have

$$
\|(I-\lambda A) x-(I-\lambda A) y\| \leq\|x-y\|,
$$

and so $(I-\lambda A)$ become a nonexpansive mapping of $K$ into $E$. 
For $L_{p}(1<p<\infty)$ spaces, we have the following relation: if $\lambda \in(0,2 \kappa /(p-1))$,

$$
\begin{aligned}
\|(I- & \lambda A) x-(I-\lambda A) y \|^{2} \\
= & \|x-y-\lambda(A x-A y)\|^{2} \\
\leq & \|x-y\|^{2}-2 \lambda\langle A x-A y, j(x-y)\rangle \\
& +(p-1) \lambda^{2}\|A x-A y\|^{2} \\
& \leq\|x-y\|^{2}-\lambda(2 \kappa-(p-1) \lambda)\|A x-A y\|^{2} \\
& \leq\|x-y\|^{2} .
\end{aligned}
$$

Also if $E$ is a Hilbert space and we choose $\lambda \in(0,2 \kappa)$, then $(I-\lambda A)$ is nonexpansive.

\section{Path Convergence Theorems}

In the sequel, we assume for each $t \in(0,1)$ that the sequence $\left\{\sigma_{i, t}\right\}_{i}$ satisfies $\sum_{i \geq 1} \sigma_{i, t}=1-t$ and the sequences $\left\{\alpha_{n}\right\},\left\{\sigma_{i, n}\right\}_{i} \subset$ $(0,1)$, satisfy $\sum_{i \geq 1} \sigma_{i, n}=1-\alpha_{n}$.

For a countable family of nonexpansive mappings $\left\{T_{i}\right\}$ of $E$, we denote a set $\mathcal{N}_{\mathscr{I}}:=\left\{i \in \mathbb{N}: T_{i} \neq I\right\}$ ( $I$ being the identity mapping on $E$ ).

Let $K$ be a nonempty closed and convex subset of a real $q$-uniformly smooth Banach space $E$ and $P_{K}$ a nonexpansive projection of $E$ onto $K$. For some real number $\kappa>0$, let $A$ : $K \rightarrow E$ be a $\kappa$-inverse strongly accretive mapping. For some real numbers $\delta \in(0,1), \lambda \in\left(0,\left(q \kappa / d_{q}\right)^{1 /(q-1)}\right)$, and $r>0$ arbitrarily chosen but fixed and for each $t \in(0,1)$, define a map $T_{t}: E \rightarrow E$ by $u \in E$, arbitrary and fixed

$$
\begin{aligned}
& G(y, \eta)+\frac{1}{r}\langle\eta-y, j(y-x)\rangle \geq 0, \quad \forall \eta \in K, \\
& T_{t} x=t u+(1-\delta)(1-t) x+\delta \sum_{i \geq 1} \sigma_{i, t} T_{i} P_{K}(y-\lambda A y),
\end{aligned}
$$

$\forall x \in E$.

Then, $T_{t}$ is a strict contraction on $E$.

For $x^{1}, x^{2} \in E, y^{1}=T_{r} x^{1}, y^{2}=T_{r} x^{2}$, we have

$$
\begin{aligned}
\left\|T_{t} x^{1}-T_{t} x^{2}\right\| \leq & (1-t)(1-\delta)\left\|x^{1}-x^{2}\right\| \\
& +\delta \sum_{i \geq 1} \sigma_{i, t} \| T_{i} P_{K}\left(y^{1}-\lambda A y^{1}\right) \\
& -T_{i} P_{K}\left(y^{2}-\lambda A y^{2}\right) \| \\
= & (1-t)(1-\delta)\left\|x^{1}-x^{2}\right\| \\
& +\delta \sum_{i \geq 1} \sigma_{i, t} \| T_{i} P_{K}(I-\lambda A) T_{r} x^{1} \\
& -T_{i} P_{K}(I-\lambda A) T_{r} x^{2} \| \\
\leq & (1-t)\left\|x^{1}-x^{2}\right\| .
\end{aligned}
$$

Thus, for each $t \in(0,1)$, there exists a unique $z_{t} \in E$ such that

$$
\begin{aligned}
& G(y, \eta)+\frac{1}{r}\left\langle\eta-y, j\left(y-z_{t}\right)\right\rangle \geq 0, \quad \forall \eta \in K, \\
& z_{t}=t u+(1-\delta)(1-t) z_{t}+\delta \sum_{i \geq 1} \sigma_{i, t} T_{i} P_{K}(y-\lambda A y) .
\end{aligned}
$$

Lemma 10. Let $E$ be a real q-uniformly smooth Banach space which is also uniformly convex. Let $K$ be a closed, convex, and nonempty subset of $E$. For $t \in(0,1)$, let $\left\{z_{t}\right\}$ be a net satisfying (25), and assume that $\mathscr{F}:=\bigcap_{i=1}^{\infty} F\left(T_{i} P_{K}(I-\lambda A) T_{r}\right) \neq \emptyset$. Then, $\left\{z_{t}\right\}$ is bounded and admits at most one accumulation point in $\mathscr{F}$ as $t \rightarrow 0$.

Proof. Let $x^{*} \in \mathscr{F}$. Then, using (25), we have

$$
\begin{aligned}
& \left\|z_{t}-x^{*}\right\|^{2} \\
& =\left\langle t\left(u-x^{*}\right)+(1-t)(1-\delta)\left(z_{t}-x^{*}\right)\right. \\
& \quad+\delta \sum_{i \geq 1} \sigma_{i, t}\left(T_{i} P_{K}\left(T_{r} z_{t}-\lambda A T_{r} z_{t}\right)-x^{*}\right), \\
& \left.\quad j\left(z_{t}-x^{*}\right)\right\rangle \leq t\left\langle u-x^{*}, j\left(z_{t}-x^{*}\right)\right\rangle \\
& +(1-t)(1-\delta)\left\|z_{t}-x^{*}\right\|^{2}+\delta \sum_{i \geq 1} \sigma_{i, t}\left\|z_{t}-x^{*}\right\|^{2} \\
& =t\left\langle u-x^{*}, j\left(z_{t}-x^{*}\right)\right\rangle+(1-t)\left\|z_{t}-x^{*}\right\|^{2},
\end{aligned}
$$

which implies

$$
\left\|z_{t}-x^{*}\right\| \leq\left\|u-x^{*}\right\|
$$

Thus, $\left\{z_{t}\right\}$ is bounded.

Now, assume for the sake of contradiction that $x^{\prime}$ and $x^{*}$ are two distinct accumulation points of $\left\{z_{t}\right\}$ in $\mathscr{F}$; then, there exists a subnet $\left\{z_{t_{s}}\right\}$ of $\left\{z_{t}\right\}$ such that $z_{t_{s}} \rightarrow x^{\prime}$ as $s \rightarrow \infty$, and so we have the following estimates:

$$
\begin{aligned}
& \left\|z_{t_{s}}-x^{*}\right\|^{2} \\
& =\left\langle t_{s}\left(u-x^{*}\right)+\left(1-t_{s}\right)(1-\delta)\left(z_{t_{s}}-x^{*}\right)\right. \\
& \left.\quad+\delta \sum_{i \geq 1} \sigma_{i, t}\left(T_{i} P_{K}\left(z_{t_{s}}-\lambda A z_{t_{s}}\right)-x^{*}\right), j\left(z_{t_{s}}-x^{*}\right)\right\rangle \\
& \leq t_{s}\left\langle u-x^{*}, j\left(z_{t_{s}}-x^{*}\right)\right\rangle+\left(1-t_{s}\right)\left\|z_{t_{s}}-x^{*}\right\|^{2}
\end{aligned}
$$

so that

$$
\left\|z_{t_{s}}-x^{*}\right\|^{2} \leq\left\langle u-x^{*}, j\left(z_{t_{s}}-x^{*}\right)\right\rangle,
$$

and since $z_{t_{s}} \rightarrow x^{\prime}$ as $s \rightarrow \infty$, we get from (29)

$$
\left\|x^{\prime}-x^{*}\right\|^{2} \leq\left\langle u-x^{*}, j\left(x^{\prime}-x^{*}\right)\right\rangle .
$$


Applying similar argument to $x^{*}$ as an accumulation point of $\left\{z_{t}\right\}$ in $\mathscr{F}$, we also get

$$
\left\|x^{*}-x^{\prime}\right\|^{2} \leq\left\langle u-x^{\prime}, j\left(x^{*}-x^{\prime}\right)\right\rangle .
$$

Adding these last two inequalities, we get

$$
2\left\|x^{*}-x^{\prime}\right\|^{2} \leq\left\|x^{*}-x^{\prime}\right\|^{2}
$$

a contradiction, and thus $x^{\prime}=x^{*}$. This completes the proof.

Lemma 11. Let $E$ be a real q-uniformly smooth Banach space which is also uniformly convex. Let $K$ be a closed, convex, and nonempty subset of E. Let $r \in(0,1)$ be fixed and $\left\{t_{n}\right\} \subset(0,1)$ such that $\lim _{n \rightarrow \infty} t_{n}=0$ and $\lim _{n \rightarrow \infty}\left(t_{n} / \sigma_{i, n}\right)=0$ for all $i \in \mathcal{N}_{\mathscr{g}}$. Let $\left\{z_{t_{n}}\right\}$ be a sequence satisfying (25), and let $\mathscr{F}:=$ $\bigcap_{i=1}^{\infty} F\left(T_{i} P_{K}(I-\lambda A) T_{r}\right) \neq \emptyset$. Then, $\lim _{n \rightarrow \infty} \| z_{t_{n}}-\left(T_{i} P_{K}(I-\right.$ $\lambda A)) T_{r} z_{t_{n}} \|=0$, for all $i \in \mathbb{N}$.

Proof. For $i \in \mathbb{N}$ and $x^{*} \in \mathscr{F}$, we have the following estimates (using Lemma 7 establishing the existence of $g$ ):

$$
\begin{aligned}
& g\left(\left\|\left(T_{i} P_{K}(I-\lambda A)\right) T_{r} z_{t_{n}}-z_{t_{n}}\right\|\right) \\
&=g\left(\left\|\left[x^{*}-\left(T_{i} P_{K}(I-\lambda A)\right) T_{r} z_{t_{n}}\right]-\left[x^{*}-z_{t_{n}}\right]\right\|\right) \\
& \leq\left\|x^{*}-\left(T_{i} P_{K}(I-\lambda A)\right) T_{r} z_{t_{n}}\right\|^{2} \\
&-2\left\langle x^{*}-\left(T_{i} P_{K}(I-\lambda A)\right) T_{r} z_{t_{n}}, j\left(x^{*}-z_{t_{n}}\right)\right\rangle \\
&+\left\|x^{*}-z_{t_{n}}\right\|^{2} \leq\left\|x^{*}-z_{t_{n}}\right\|^{2}-2 \\
& \times\left\langle x^{*}-z_{t_{n}}+z_{t_{n}}-\left(T_{i} P_{K}(I-\lambda A)\right) T_{r} z_{t_{n}}, j\left(x^{*}-z_{t_{n}}\right)\right\rangle \\
&+\left\|x^{*}-z_{t_{n}}\right\|^{2} \\
&= 2\left\langle z_{t_{n}}-\left(T_{i} P_{K}(I-\lambda A)\right) T_{r} z_{t_{n}}, j\left(z_{t_{n}}-x^{*}\right)\right\rangle .
\end{aligned}
$$

Using (25), we have

$$
\begin{aligned}
\left\langle z_{t_{n}}-\right. & \left.x^{*}, j\left(z_{t_{n}}-x^{*}\right)\right\rangle \\
= & t_{n}\left\langle u-x^{*}, j\left(z_{t_{n}}-x^{*}\right)\right\rangle \\
& +\left(1-t_{n}\right)(1-\delta)\left\langle z_{t_{n}}-x^{*}, j\left(z_{t_{n}}-x^{*}\right)\right\rangle+\delta \sum_{i \geq 1} \sigma_{i, n} \\
& \times\left\langle\left(T_{i} P_{K}(I-\lambda A)\right) T_{r} z_{t_{n}}-z_{t_{n}}+z_{t_{n}}-x^{*}, j\left(z_{t_{n}}-x^{*}\right)\right\rangle \\
= & t_{n}\left\langle u-x^{*}, j\left(z_{t_{n}}-x^{*}\right)\right\rangle \\
& +\delta \sum_{i \geq 1} \sigma_{i, n}\left\langle\left(T_{i} P_{K}(I-\lambda A)\right) T_{r} z_{t_{n}}\right. \\
& \left.\quad-z_{t_{n}}, j\left(z_{t_{n}}-x^{*}\right)\right\rangle \\
& +\left(1-t_{n}\right)\left\langle z_{t_{n}}-x^{*}, j\left(z_{t_{n}}-x^{*}\right)\right\rangle
\end{aligned}
$$

which implies

$$
\begin{gathered}
\delta \sum_{i \geq 1} \sigma_{i, n}\left\langle z_{t_{n}}-\left(T_{i} P_{K}(I-\lambda A)\right) T_{r} z_{t_{n}}, j\left(z_{t_{n}}-x^{*}\right)\right\rangle \\
=t_{n}\left\langle u-z_{t_{n}}, j\left(z_{t_{n}}-x^{*}\right)\right\rangle .
\end{gathered}
$$

Using this and (33), we get

$$
\begin{gathered}
\frac{\delta}{2} \sum_{i \geq 1} \sigma_{i, n} g\left(\left\|\left(T_{i} P_{K}(I-\lambda A)\right) T_{r} z_{t_{n}}-z_{t_{n}}\right\|\right) \\
\leq t_{n}\left\langle u-z_{t_{n}}, j\left(z_{t_{n}}-x^{*}\right)\right\rangle .
\end{gathered}
$$

Thus,

$$
\begin{aligned}
& \frac{\delta}{2} g\left(\left\|\left(T_{i} P_{K}(I-\lambda A)\right) T_{r} z_{t_{n}}-z_{t_{n}}\right\|\right) \\
& \quad \leq \frac{t_{n}}{\sigma_{i, n}}\left\langle u-z_{t_{n}}, j\left(z_{t_{n}}-x^{*}\right)\right\rangle, \quad \forall i \in \mathbb{N} .
\end{aligned}
$$

Since $\left\{z_{t_{n}}\right\}$ is bounded and $t_{n} / \sigma_{i, n} \rightarrow 0$ as $n \rightarrow \infty$, we have $\lim _{n \rightarrow \infty} g\left(\left\|\left(T_{i} P_{K}(I-\lambda A)\right) T_{r} z_{t_{n}}-z_{t_{n}}\right\|\right)=0$ for all $i \in \mathbb{N}$. By property of $g, \lim _{n \rightarrow \infty}\left\|\left(T_{i} P_{K}(I-\lambda A)\right) T_{r} z_{t_{n}}-z_{t_{n}}\right\|=0$ for all $i \in \mathbb{N}$. This completes the proof.

Theorem 12. Let $E$ be a real q-uniformly smooth Banach space which is also uniformly convex. Let $K$ be a closed, convex, and nonempty subset of E. Let $r \in(0,1)$ be fixed and $\left\{t_{n}\right\} \subset(0,1)$ such that $\lim _{n \rightarrow \infty} t_{n}=0$ and $\lim _{n \rightarrow \infty}\left(t_{n} / \sigma_{i, n}\right)=0$ for all $i \in \mathcal{N}_{\mathscr{g}}$. Let $\left\{z_{t_{n}}\right\}$ be a sequence satisfying (25), and let $\mathscr{F}:=$ $\bigcap_{i=1}^{\infty} F\left(T_{i} P_{K}(I-\lambda A) T_{r}\right) \neq \emptyset$. If the duality mapping $j$ of $E$ is weakly sequentially continuous, then $\left\{z_{t_{n}}\right\}$ converges strongly to an element in $\mathscr{F}$.

Proof. Since $\left\{z_{t_{n}}\right\}$ is bounded, there exists a subsequence say $\left\{z_{t_{n_{k}}}\right\}$ of $\left\{z_{t_{n}}\right\}$ that converges weakly to some point $z \in K$. Using demiclosedness property of $\left[I-\left(T_{i} P_{K}(I-\lambda A)\right) T_{r}\right]$ at 0 for $i \in \mathbb{N}$, and the fact that $\lim _{k \rightarrow \infty} \|\left(T_{i} P_{K}(I-\lambda A)\right) T_{r} z_{t_{n_{k}}}-$ $z_{t_{n_{k}}} \|=0$, we get that $z$ is a point in $\mathscr{F}$. We also observe from (33) that

$$
\begin{aligned}
& \left\|z_{t_{n_{k}}}-\mathrm{z}\right\|^{2} \\
& =\left\langle t_{n_{k}}(u-z)+\left(1-t_{n_{k}}\right)(1-\delta)\left(z_{t_{n_{k}}}-z\right)\right. \\
& \left.+\delta \sum_{i \geq 1} \sigma_{i, n_{k}}\left(\left(T_{i} P_{K}(I-\lambda A)\right) T_{r} z_{t_{n_{k}}}-z\right), j\left(z_{t_{n_{k}}}-z\right)\right\rangle \\
& \leq t_{n_{k}}\left\langle u-z, j\left(z_{t_{n_{k}}}-z\right)\right\rangle+\left(1-t_{n_{k}}\right)(1-\delta)\left\|z_{t_{n_{k}}}-z\right\|^{2} \\
& \quad+\delta \sum_{i \geq 1} \sigma_{i, n_{k}}\left\|z_{t_{n_{k}}}-z\right\|^{2} \\
& =t_{n_{k}}\left\langle u-z, j\left(z_{t_{n_{k}}}-z\right)\right\rangle+\left(1-t_{n_{k}}\right)\left\|z_{t_{n_{k}}}-z\right\|^{2}
\end{aligned}
$$


which implies

$$
\left\|z_{t_{n_{k}}}-z\right\|^{2} \leq\left\langle u-z, j\left(z_{t_{n_{k}}}-z\right)\right\rangle
$$

Since $j$ admits weak sequential continuity, the last inequality implies that the subsequence $\left\{z_{t_{n_{k}}}\right\}$ converges strongly to $z$, and since $\left\{z_{t_{n}}\right\}$ admits unique accumulation point in $\mathscr{F}$, then it converges strongly to $z$. This completes the proof.

The following corollary follows from Theorem 12 .

Corollary 13. Let $E$ be a real $L_{p}$ space, $(1<p<\infty)$. Let $K$, $\left\{t_{n}\right\}, \mathscr{F}$, and $\left\{z_{t_{n}}\right\}$ be as in Theorem 12. Then, $\left\{z_{t_{n}}\right\}$ converges strongly to an element of $\mathscr{F}$.

Theorem 14. Let E be a real q-uniformly smooth Banach space which is also uniformly convex. Let $K$ be a closed, convex, and nonempty subset of E. Let $r \in(0,1)$ be fixed and $\left\{t_{n}\right\}$ a sequence in $(0,1)$ such that $\lim _{n \rightarrow \infty} t_{n}=0$ and $\lim _{n \rightarrow \infty}\left(t_{n} / \sigma_{i, n}\right)=0$ for all $i \in \mathcal{N}_{\mathscr{g}}$. Let $\left\{z_{t_{n}}\right\}$ be a sequence satisfying (25), and let $\mathscr{F}:=\bigcap_{i=1}^{\infty} F\left(T_{i} P_{K}(I-\lambda A) T_{r}\right) \neq \emptyset$. If for at least one $i$ in $\mathbb{N}$, $T_{i} P_{K}(I-\lambda A) T_{r}$ is demicompact, then $\left\{z_{t_{n}}\right\}$ converges strongly to an element of $\mathscr{F}$.

Proof. For some fixed $j_{0} \in \mathbb{N}$, let $T_{j_{0}} P_{K}(I-\lambda A) T_{r}$ be demicompact. Since $\lim _{n \rightarrow \infty}\left\|T_{j_{0}} P_{K}(I-\lambda A) T_{r} z_{t_{n}}-z_{t_{n}}\right\|=0$, there exists a subsequence say $\left\{z_{t_{n_{k}}}\right\}$ of $\left\{z_{t_{n}}\right\}$ that converges strongly to some point $z \in E$. By continuity of $T_{i} P_{K}(I-\lambda A) T_{r}$ for all $i \in \mathbb{N}$, we have that $z \in \mathscr{F}$. But the sequence $\left\{z_{t_{n}}\right\}$ admits unique accumulation point in $\mathscr{F}$; so, it converges strongly to $z$.

The following corollaries follow from Theorem 14.

Corollary 15. Let $E$ be a real $L_{p}$ space, $(1<p<\infty)$. Let $K$, $\left\{t_{n}\right\}, \mathscr{F}$, and $\left\{z_{t_{n}}\right\}$ be as in Theorem 14. If for at least one $i \in \mathbb{N}$, the map $T_{i} P_{K}(I-\lambda A) T_{r}$ is demicompact, then $\left\{z_{t_{n}}\right\}$ converges strongly to an element of $\mathscr{F}$.

Corollary 16. Let $K$ be a closed, convex, and nonempty subset of a real Hilbert space $H$. Let $\left\{t_{n}\right\}, \mathscr{F}$, and $\left\{z_{t_{n}}\right\}$ be as in Theorem 14. Then, $\left\{z_{t_{n}}\right\}$ converges strongly to an element of $\mathscr{F}$.

\section{Iterative Convergence Theorem}

We now state and prove the following theorem.

Theorem 17. Let $E$ be a real q-uniformly smooth Banach space which is also uniformly convex. Let $K$ be a closed, convex, and nonempty subset of $E$. For some $\kappa>0$, let $T_{i}: K \rightarrow$ $E i \in \mathbb{N}$ and $A: K \rightarrow E$ be a family of nonexpansive maps and $a$-inverse strongly accretive map, respectively. Let $G: K \times K \rightarrow \mathbb{R}$ be a bifunction satisfying (A1)-(A4). Let $P_{K}$ be a nonexpansive projection of $E$ onto $K$. For some fixed real numbers $r, \delta \in(0,1)$ and $\lambda \in\left(0,\left(q \kappa / d_{q}\right)^{1 /(q-1)}\right)$, define a sequence $\left\{x_{n}\right\}$ iteratively by $x_{1}, u \in E$ and $n \in \mathbb{N}$ as

$$
\begin{aligned}
G\left(y_{n}, \eta\right)+\frac{1}{r}\left\langle\eta-y_{n}, j\left(y_{n}-x_{n}\right)\right\rangle \geq 0, \quad \forall \eta \in K, \\
x_{n+1}=\alpha_{n} u+(1-\delta)\left(1-\alpha_{n}\right) x_{n}+\delta \sum_{i \geq 1} \sigma_{i, n} T_{i} P_{K} \\
\quad \times\left(y_{n}-\lambda A y_{n}\right),
\end{aligned}
$$

where $\left\{\alpha_{n}\right\},\left\{\sigma_{i, n}\right\} \subset(0,1)$ are sequences satisfying the following conditions:

(i) $\lim _{n \rightarrow \infty} \alpha_{n}=0$,

(ii) $\sum_{n=1}^{\infty} \alpha_{n}=\infty$,

(iii) $\lim _{n \rightarrow \infty} \sum_{i \geq 1}\left|\sigma_{i, n+1}-\sigma_{i, n}\right|=0$.

Let $F:=\left[\bigcap_{i=1}^{\infty} F\left(T_{i}\right)\right] \bigcap \operatorname{EP}(G) \bigcap \operatorname{VI}(K, A) \neq \emptyset$. If either the duality map $j$ of $E$ is weakly sequentially continuous or for at least one $i \in \mathbb{N}, T_{i} P_{K}(I-\lambda A) T_{r}$ is demicompact, then $\left\{x_{n}\right\}$ converges strongly to some element in $F$.

Proof. Let $x^{*} \in \mathscr{F}$ then, we claim that $\left\|x_{n}-x^{*}\right\| \leq \max \{\| u-$ $\left.x^{*}\|,\| x_{1}-x^{*} \|\right\}$ for all $n \geq 1$. It is clear that the claim is true for $n=1$. Assume that it is true for $n=k$ for some $k \geq 1, k \in \mathbb{N}$. Then,

$$
\begin{aligned}
\| x_{k+1} & -x^{*} \| \\
\leq & \alpha_{k}\left\|u-x^{*}\right\|+\left(1-\alpha_{k}\right)(1-\delta)\left\|x_{k}-x^{*}\right\| \\
& +\delta \sum_{i \geq 1} \sigma_{i, k}\left\|T_{i} P_{K}(I-\lambda A) T_{r} x_{k}-T_{i} P_{K}(I-\lambda A) T_{r} x^{*}\right\| \\
\leq & \alpha_{k}\left\|u-x^{*}\right\|+\left(1-\alpha_{k}\right)\left\|x_{k}-x^{*}\right\| \\
\leq & \max \left\{\left\|u-x^{*}\right\|,\left\|x_{1}-x^{*}\right\|\right\} .
\end{aligned}
$$

Hence, the result, and so $\left\{x_{n}\right\}$ is bounded. Furthermore, $\left\{y_{n}\right\}$, $\left\{T_{i} P_{K}\left(y_{n}-\lambda A y_{n}\right)\right\}$, and $\left\{A y_{n}\right\}$ are each bounded.

We now show that $\lim _{n \rightarrow \infty}\left\|x_{n+1}-x_{n}\right\|=0$. Note that $y_{n}=T_{r} x_{n}, y_{n+1}=T_{r} x_{n+1}$, so that

$$
\begin{aligned}
\left\|y_{n+1}-y_{n}\right\| & =\left\|T_{r} x_{n+1}-T_{r} x_{n}\right\| \\
& \leq\left\|x_{n+1}-x_{n}\right\| .
\end{aligned}
$$

Define two sequences $\left\{\beta_{n}\right\}$ and $\left\{w_{n}\right\}$ by $\beta_{n}:=(1-\delta) \alpha_{n}+\delta$ and $w_{n}:=\left(x_{n+1}-x_{n}+\beta_{n} x_{n}\right) / \beta_{n}$. Then,

$$
w_{n}=\frac{\alpha_{n} u+\delta \sum_{i \geq 1} \sigma_{i, n} T_{i} P_{K}\left(y_{n}-\lambda A y_{n}\right)}{\beta_{n}} .
$$


Observe that $\left\{w_{n}\right\}$ is bounded and that

$$
\begin{aligned}
\| w_{n+1}- & w_{n}\|-\| x_{n+1}-x_{n} \| \\
\leq & \left|\frac{\alpha_{n+1}}{\beta_{n+1}}-\frac{\alpha_{n}}{\beta_{n}}\right|\|u\|+\left|\frac{\delta\left(1-\alpha_{n+1}\right)}{\beta_{n+1}}-1\right|\left\|x_{n+1}-x_{n}\right\| \\
& +\frac{\delta M}{\beta_{n+1}} \sum_{i \geq 1}\left|\sigma_{i, n+1}-\sigma_{i, n}\right| \\
& +\frac{\delta M}{\beta_{n+1} \beta_{n}}\left|\beta_{n}-\beta_{n+1}\right|,
\end{aligned}
$$

for some positive real number $M$. This implies

$$
\limsup _{n \rightarrow \infty}\left(\left\|w_{n+1}-w_{n}\right\|-\left\|x_{n+1}-x_{n}\right\|\right) \leq 0,
$$

and by Lemma $4, \lim _{n \rightarrow \infty}\left\|w_{n}-x_{n}\right\|=0$. Hence,

$$
\left\|x_{n+1}-x_{n}\right\|=\beta_{n}\left\|w_{n}-x_{n}\right\| \longrightarrow 0 \quad \text { as } n \longrightarrow \infty \text {. }
$$

From (42) and (46), we have

$$
\left\|y_{n+1}-y_{n}\right\| \longrightarrow 0 \quad \text { as } n \longrightarrow \infty
$$

From (40), we have $x_{n+1}-x_{n}=\alpha_{n}\left(u-x_{n}\right)+$ $\delta \sum_{i \geq 1} \sigma_{i, n}\left[T_{i} P_{K}\left(y_{n}-\lambda A y_{n}\right)-x_{n}\right]$ which implies

$$
\begin{gathered}
\delta\left\|\sum_{i \geq 1} \sigma_{i, n}\left[T_{i} P_{K}\left(y_{n}-\lambda A y_{n}\right)-x_{n}\right]\right\| \\
\leq\left\|x_{n+1}-x_{n}\right\|+\alpha_{n}\left\|u-x_{n}\right\|,
\end{gathered}
$$

and thus $\lim _{n \rightarrow \infty}\left\|\sum_{i \geq 1} \sigma_{i, n}\left[T_{i} P_{K}\left(y_{n}-\lambda A y_{n}\right)-x_{n}\right]\right\|=0$. Let $\left\{t_{n}\right\}$ be a real sequence in $(0,1)$ satisfying the following conditions:

$$
\begin{aligned}
& \lim _{n \rightarrow \infty} t_{n}=0, \quad \sum_{i \geq 1} \sigma_{i, n}=\left(1-t_{n}\right), \\
& \lim _{n \rightarrow \infty} \frac{\left\|\sum_{i \geq 1} \sigma_{i, n}\left[T_{i} P_{K}\left(y_{n}-\lambda A y_{n}\right)-x_{n}\right]\right\|}{t_{n}}=0 .
\end{aligned}
$$

Let $z_{t_{n}} \in K$ be the unique fixed point satisfying (25) for each $n \in \mathbb{N}$, and let $z_{t_{n}} \rightarrow z \in \mathscr{F}$ as $n \rightarrow \infty$. Using (25) and Lemma 2, we have the following estimates:

$$
\begin{aligned}
& \left\|z_{t_{n}}-x_{n}\right\|^{2} \\
& \leq \|(1-\delta)\left(1-t_{n}\right)\left(z_{t_{n}}-x_{n}\right) \\
& +\delta \sum_{i \geq 1} \sigma_{i, n}\left(T_{i} P_{K}(I-\lambda A) T_{r} z_{t_{n}}-T_{i} P_{K}(I-\lambda A) T_{r} x_{n}\right. \\
& \left.+T_{i} P_{K}(I-\lambda A) T_{r} x_{n}-x_{n}\right) \|^{2}+2 t_{n}\left\langle u-x_{n}, j\left(z_{t_{n}}-x_{n}\right)\right\rangle \\
& \leq\left[(1-\delta)\left(1-t_{n}\right)\left\|z_{t_{n}}-x_{n}\right\|+\delta\left(1-t_{n}\right)\left\|z_{t_{n}}-x_{n}\right\|\right. \\
& \left.+\left\|\delta \sum_{i \geq 1} \sigma_{i, n}\left[T_{i} P_{K}(I-\lambda A) T_{r} x_{n}-x_{n}\right]\right\|\right]^{2} \\
& +2 t_{n}\left\langle u-x_{n}, j\left(z_{t_{n}}-x_{n}\right)\right\rangle \\
& =\left[\left(1-t_{n}\right)\left\|z_{t_{n}}-x_{n}\right\|\right. \\
& \left.+\left\|\delta \sum_{i \geq 1} \sigma_{i, n}\left[T_{i} P_{K}(I-\lambda A) T_{r} x_{n}-x_{n}\right]\right\|\right]^{2} \\
& +2 t_{n}\left\langle u-x_{n}, j\left(z_{t_{n}}-x_{n}\right)\right\rangle \text {. }
\end{aligned}
$$

This implies

$$
\begin{aligned}
\left\langle u-z_{t_{n}}, j\left(x_{n}-z_{t_{n}}\right)\right\rangle & \\
\leq & \frac{t_{n}}{2}\left\|z_{t_{n}}-x_{n}\right\|^{2}+\left(1-t_{n}\right)\left\|z_{t_{\mathrm{n}}}-x_{n}\right\| \\
& \times\left(\frac{\delta\left\|\sum_{i \geq 1} \sigma_{i, n}\left[T_{i} P_{K}(I-\lambda A) T_{r} x_{n}-x_{n}\right]\right\|}{t_{n}}\right) \\
& +\frac{\delta^{2}\left\|\sum_{i \geq 1} \sigma_{i, n}\left[T_{i} P_{K}(I-\lambda A) T_{r} x_{n}-x_{n}\right]\right\|^{2}}{2 t_{n}},
\end{aligned}
$$

and, hence,

$$
\limsup _{n \rightarrow \infty}\left\langle u-z_{t_{n}}, j\left(x_{n}-z_{t_{n}}\right)\right\rangle \leq 0 .
$$

Moreover,

$$
\begin{aligned}
\left\langle u-z_{t_{n}}, j\left(x_{n}-z_{t_{n}}\right)\right\rangle= & \left\langle u-z, j\left(x_{n}-z\right)\right\rangle \\
& +\left\langle u-z, j\left(x_{n}-z_{t_{n}}\right)-j\left(x_{n}-z\right)\right\rangle \\
& +\left\langle z-z_{t_{n}}, j\left(x_{n}-z_{t_{n}}\right)\right\rangle
\end{aligned}
$$


and since $j$ is norm-to-weak ${ }^{*}$ uniformly continuous on bounded sets, we have

$$
\limsup _{n \rightarrow \infty}\left\langle u-z, j\left(x_{n}-z\right)\right\rangle \leq 0 .
$$

From the recursion formula (40) and Lemma 2, we have the following:

$$
\begin{aligned}
& \left\|x_{n+1}-z\right\|^{2} \\
& =\| \alpha_{n}(u-z)+\left(1-\alpha_{n}\right)(1-\delta)\left(x_{n}-z\right) \\
& \quad+\delta \sum_{i \geq 1} \sigma_{i, n}\left[T_{i} P_{K}(I-\lambda A) T_{r} x_{n}-T_{i} P_{K}(I-\lambda A) T_{r} z\right] \|^{2} \\
& \leq \|\left(1-\alpha_{n}\right)(1-\delta)\left(x_{n}-z\right) \\
& +\delta \sum_{i \geq 1} \sigma_{i, n}\left[T_{i} P_{K}(I-\lambda A) T_{r} x_{n}-T_{i} P_{K}(I-\lambda A) T_{r} z\right] \|^{2} \\
& +2 \alpha_{n}\left\langle u-z, j\left(x_{n+1}-z\right)\right\rangle \leq\left(1-\alpha_{n}\right)\left\|x_{n}-z\right\|^{2} \\
& +2 \alpha_{n}\left\langle u-z, j\left(x_{n+1}-z\right)\right\rangle,
\end{aligned}
$$

and by Lemma 5 , we get that $\left\{x_{n}\right\}$ converges strongly to $z \in$ $\mathscr{F}$.

To complete the proof, we show that $z \in \operatorname{EP}(G) \cap$ $\mathrm{VI}(K, A)$.

We start by showing that $z \in \operatorname{EP}(G)$.

Let $x^{*} \in F$; then,

$$
\begin{aligned}
\| y_{n}- & x^{*} \|^{2} \\
& =\left\|T_{r} x_{n}-T_{r} x^{*}\right\|^{2} \\
& \leq\left\langle T_{r} x_{n}-T_{r} x^{*}, j\left(x_{n}-x^{*}\right)\right\rangle=\left\langle y_{n}-x^{*}, j\left(x_{n}-x^{*}\right)\right\rangle \\
& \leq \frac{1}{2}\left[\left\|x_{n}-x^{*}\right\|^{2}+\left\|y_{n}-x^{*}\right\|^{2}-g\left(\left\|x_{n}-y_{n}\right\|\right)\right] ;
\end{aligned}
$$

thus,

$$
\left\|y_{n}-x^{*}\right\|^{2} \leq\left\|x_{n}-x^{*}\right\|^{2}-g\left(\left\|x_{n}-y_{n}\right\|\right)
$$

Using (40) and (57), we have

$$
\begin{aligned}
& \left\|x_{n+1}-x^{*}\right\|^{2} \\
& =\| \alpha_{n}\left(u-x^{*}\right)+\left(1-\alpha_{n}\right)(1-\delta)\left(x_{n}-x^{*}\right) \\
& \quad+\delta \sum_{i \geq 1} \sigma_{i, n}\left[T_{i} P_{K}(I-\lambda A) y_{n}-T_{i} P_{K}(I-\lambda A) x^{*}\right] \|^{2} \\
& \leq \alpha_{n}\left\|u-x^{*}\right\|^{2}+\left(1-\alpha_{n}\right)(1-\delta)\left\|x_{n}-x^{*}\right\|^{2} \\
& +\delta\left(1-\alpha_{n}\right)\left\|y_{n}-x^{*}\right\|^{2} \\
& \leq \alpha_{n}\left\|u-x^{*}\right\|^{2}+\left(1-\alpha_{n}\right)(1-\delta)\left\|x_{n}-x^{*}\right\|^{2} \\
& +\delta\left(1-\alpha_{n}\right)\left[\left\|x_{n}-x^{*}\right\|^{2}-g\left(\left\|x_{n}-y_{n}\right\|\right)\right] .
\end{aligned}
$$

This implies

$$
\begin{aligned}
\delta(1 & \left.-\alpha_{n}\right) g\left(\left\|x_{n}-y_{n}\right\|\right) \\
\leq & \alpha_{n}\left\|u-x^{*}\right\|^{2}+\left\|x_{n}-x^{*}\right\|^{2} \\
& -\left\|x_{n+1}-x^{*}\right\|^{2} \leq \alpha_{n}\left\|u-x^{*}\right\|^{2} \\
& +\left\|x_{n}-x_{n+1}\right\|\left[\left\|x_{n}-x^{*}\right\|+\left\|x_{n+1}-x^{*}\right\|\right],
\end{aligned}
$$

and thus $\lim _{n \rightarrow \infty} \delta\left(1-\alpha_{n}\right) g\left(\left\|x_{n}-y_{n}\right\|\right)=0$. Using property of $g$, we get

$$
\lim _{n \rightarrow \infty}\left\|x_{n}-y_{n}\right\|=0
$$

From (60), we have $y_{n} \rightarrow z$ and $j\left(x_{n}-y_{n}\right) \rightarrow 0$ as $n \rightarrow \infty$. Since $y_{n}=T_{r} x_{n}$, we have

$$
G\left(y_{n}, \eta\right)+\frac{1}{r}\left\langle\eta-y_{n}, j\left(y_{n}-x_{n}\right)\right\rangle \geq 0, \quad \forall \eta \in K,
$$

It follows from (A2) that

$$
\left\langle\eta-y_{n}, \frac{j\left(y_{n}-x_{n}\right)}{r}\right\rangle \geq G\left(\eta, y_{n}\right),
$$

and so using (A4), we have $G(\eta, z) \leq 0$ for all $\eta \in K$. For real number $t, 0<t \leq 1$, and $\eta \in K$, let $\eta_{t}=t \eta+(1-t) z$. Clearly, $\eta_{t} \in K$. So, using (A1) and (A4), we have

$$
0=G\left(\eta_{t}, \eta_{t}\right) \leq t G\left(\eta_{t}, \eta\right)+(1-t) G\left(\eta_{t}, z\right) \leq t G\left(\eta_{t}, \eta\right) .
$$

This implies $G\left(\eta_{t}, \eta\right) \geq 0$, and using this and (A3), we have that $G(z, \eta) \geq 0$ for all $\eta \in K$; hence, $z \in \operatorname{EP}(G)$.

Next, we show that $z \in \operatorname{VI}(K, B)$.

Let $x^{*} \in F$ and $b_{n}:=P_{K}\left(y_{n}-\lambda A y_{n}\right)$; then,

$$
\begin{aligned}
\left\|b_{n}-x^{*}\right\|^{q} & =\left\|P_{K}\left(y_{n}-\lambda A y_{n}\right)-P_{K}\left(x^{*}-\lambda A x^{*}\right)\right\|^{q} \\
& \leq\left\|y_{n}-x^{*}-\lambda\left(A y_{n}-A x^{*}\right)\right\|^{q} \\
& \leq\left\|y_{n}-x^{*}\right\|^{q}+\lambda\left(d_{q} \lambda^{q-1}-q \kappa\right)\left\|A y_{n}-A x^{*}\right\|^{q} .
\end{aligned}
$$


Using recursion formula (40), we have the following estimates:

$$
\begin{aligned}
& \left\|x_{n+1}-x^{*}\right\|^{q} \\
& =\| \alpha_{n}\left(u-x^{*}\right)+\left(1-\alpha_{n}\right)(1-\delta)\left(x_{n}-x^{*}\right) \\
& +\delta \sum_{i \geq 1} \sigma_{i, n}\left[T_{i} b_{n}-x^{*}\right]\left\|^{q} \leq \alpha_{n}\right\| u-x^{*} \|^{q} \\
& +\left(1-\alpha_{n}\right)(1-\delta)\left\|x_{n}-x^{*}\right\|^{q} \\
& +\left(1-\alpha_{n}\right) \delta\left\|b_{n}-x^{*}\right\|^{q} \leq \alpha_{n}\left\|u-x^{*}\right\|^{q} \\
& +\left(1-\alpha_{n}\right)(1-\delta)\left\|x_{n}-x^{*}\right\|^{q}+\left(1-\alpha_{n}\right) \delta \\
& \times\left[\left\|x_{n}-x^{*}\right\|^{q}+\lambda\left(d_{q} \lambda^{q-1}-q \kappa\right)\left\|A y_{n}-A x^{*}\right\|^{q}\right] \\
& \leq \alpha_{n}\left\|u-x^{*}\right\|^{q}+\left\|x_{n}-x^{*}\right\|^{q}+\left(1-\alpha_{n}\right) \delta \lambda\left(d_{q} \lambda^{q-1}-q \kappa\right) \\
& \times\left\|A y_{n}-A x^{*}\right\|^{q} \text {, }
\end{aligned}
$$

which implies, by Mean Value Theorem, that

$$
\begin{aligned}
-(1 & \left.-\alpha_{n}\right) \delta \lambda\left(d_{q} \lambda^{q-1}-q \kappa\right)\left\|A y_{n}-A x^{*}\right\|^{q} \\
& \leq \alpha_{n}\left\|u-x^{*}\right\|^{q}+\left\|x_{n}-x^{*}\right\|^{q}-\left\|x_{n+1}-x^{*}\right\|^{q} \\
& \leq \alpha_{n}\left\|u-x^{*}\right\|^{q}+q \sigma_{n}^{q-1} \mid\left\|x_{n}-x^{*}\right\|-\left\|x_{n+1}-x^{*}\right\| \\
& \leq \alpha_{n}\left\|u-x^{*}\right\|^{q}+q \sigma_{n}^{q-1}\left\|x_{n}-x_{n+1}\right\|,
\end{aligned}
$$

where $\sigma_{n}$ is some nonnegative real number between $\left\|x_{n}-x^{*}\right\|$ and $\left\|x_{n+1}-x^{*}\right\|$ for each $n$. Since $\left\{x_{n}\right\}$ is bounded, $\alpha_{n} \rightarrow 0$, and $\left\|x_{n}-x_{n+1}\right\| \rightarrow 0$ as $n \rightarrow \infty$, we have $\left\|A y_{n}-A x^{*}\right\| \rightarrow 0$ as $n \rightarrow \infty$.

We also have the following:

$$
\begin{aligned}
\| b_{n} & -x^{*} \|^{2} \\
& =\left\|P_{K}\left(y_{n}-\lambda A y_{n}\right)-P_{K}\left(x^{*}-\lambda A x^{*}\right)\right\|^{2} \\
\leq & \left\langle y_{n}-\lambda A y_{n}-\left(x^{*}-\lambda A x^{*}\right), j\left(b_{n}-x^{*}\right)\right\rangle \\
& =\left\langle y_{n}-x^{*}, j\left(b_{n}-x^{*}\right)\right\rangle-\lambda\left\langle A y_{n}-A x^{*}, j\left(b_{n}-x^{*}\right)\right\rangle \\
\leq & \frac{1}{2}\left[\left\|b_{n}-x^{*}\right\|^{2}+\left\|y_{n}-x^{*}\right\|^{2}-g\left(\left\|b_{n}-y_{n}\right\|\right)\right] \\
& -\lambda\left\langle A y_{n}-A x^{*}, j\left(b_{n}-x^{*}\right)\right\rangle
\end{aligned}
$$

so that

$$
\begin{gathered}
\left\|b_{n}-x^{*}\right\|^{2} \leq\left\|x_{n}-x^{*}\right\|^{2}-g\left(\left\|b_{n}-y_{n}\right\|\right) \\
-2 \lambda\left\langle A y_{n}-A x^{*}, j\left(b_{n}-x^{*}\right)\right\rangle .
\end{gathered}
$$

We then have

$$
\begin{aligned}
& \left\|x_{n+1}-x^{*}\right\|^{2} \\
& =\| \alpha_{n}\left(u-x^{*}\right)+\left(1-\alpha_{n}\right)(1-\delta)\left(x_{n}-x^{*}\right) \\
& \quad+\delta \sum_{i \geq 1} \sigma_{i, n}\left[T_{i} b_{n}-x^{*}\right]\left\|^{2} \leq \alpha_{n}\right\| u-x^{*} \|^{2} \\
& +\left(1-\alpha_{n}\right)(1-\delta)\left\|x_{n}-x^{*}\right\|^{2}+\left(1-\alpha_{n}\right) \delta\left\|b_{n}-x^{*}\right\|^{2} \\
& \leq \alpha_{n}\left\|u-x^{*}\right\|^{2}+\left(1-\alpha_{n}\right)(1-\delta)\left\|x_{n}-x^{*}\right\|^{2} \\
& +\left(1-\alpha_{n}\right) \delta\left[\left\|x_{n}-x^{*}\right\|^{2}-g\left(\left\|b_{n}-x_{n}\right\|\right)\right. \\
& \left.\quad-2 \lambda\left\langle A y_{n}-A x^{*}, j\left(b_{n}-x^{*}\right)\right\rangle\right] \\
& =\alpha_{n}\left\|u-x^{*}\right\|^{2}+\left(1-\alpha_{n}\right)\left\|x_{n}-x^{*}\right\|^{2}-\left(1-\alpha_{n}\right) \\
& \quad \times \delta g\left(\left\|b_{n}-y_{n}\right\|\right)-2 \delta \lambda\left(1-\alpha_{n}\right)\left\langle A y_{n}-A x^{*}, j\left(b_{n}-x^{*}\right)\right\rangle,
\end{aligned}
$$

and so

$$
\begin{aligned}
\left(1-\alpha_{n}\right) \delta g\left(\left\|b_{n}-y_{n}\right\|\right) \\
\leq \alpha_{n}\left\|u-x^{*}\right\|^{2}+\left\|x_{n}-x^{*}\right\|^{2}-\left\|x_{n+1}-x^{*}\right\|^{2} \\
-2 \delta \lambda\left(1-\alpha_{n}\right)\left\langle A y_{n}-A x^{*}, j\left(b_{n}-x^{*}\right)\right\rangle .
\end{aligned}
$$

As $\alpha_{n} \rightarrow 0,\left\|x_{n}-x_{n+1}\right\| \rightarrow 0$ and $\left\|A x_{n}-A x^{*}\right\| \rightarrow 0$ as $n \rightarrow \infty$, we get

$$
\lim _{n \rightarrow \infty}\left(1-\alpha_{n}\right) \delta g\left(\left\|b_{n}-y_{n}\right\|\right)=0,
$$

which implies

$$
\lim _{n \rightarrow \infty}\left\|b_{n}-y_{n}\right\|=0
$$

Let

$$
M v= \begin{cases}A v+N_{K} v, & v \in K, \\ \emptyset, & v \notin K .\end{cases}
$$

Then, $M$ is maximal accretive. Let $\mathrm{GF}(M)$ denote the graph of $M$.

Let $(v, w) \in \mathrm{GF}(M)$. Since $w-A v \in N_{K} v$ and $b_{n} \in K$, we have $\left\langle w-A v, j_{q}\left(v-b_{n}\right)\right\rangle \geq 0$ by definition of $N_{K} v$. Also, as $b_{n}=P_{K}\left(y_{n}-\lambda A y_{n}\right)$ (using property of the projection $P_{K}$ ), we have

$$
\left\langle b_{n}-\left(y_{n}-\lambda A y_{n}\right), j_{q}\left(v-b_{n}\right)\right\rangle \geq 0
$$

and, hence,

$$
\left\langle\frac{b_{n}-y_{n}}{\lambda}+A y_{n}, j_{q}\left(v-b_{n}\right)\right\rangle \geq 0 .
$$


Using this, we obtain the following estimates:

$$
\begin{aligned}
\left\langle w, j_{q}\left(v-b_{n}\right)\right\rangle \geq & \left\langle A v, j_{q}\left(v-b_{n}\right)\right\rangle \\
\geq & \left\langle A v, j_{q}\left(v-b_{n}\right)\right\rangle \\
& -\left\langle\frac{b_{n}-y_{n}}{\lambda}+A y_{n}, j_{q}\left(v-b_{n}\right)\right\rangle \\
= & \left\langle A v-\frac{b_{n}-y_{n}}{\lambda}-A y_{n}, j_{q}\left(v-b_{n}\right)\right\rangle \\
= & \left\langle A v-A b_{n}, j_{q}\left(v-b_{n}\right)\right\rangle \\
& +\left\langle A b_{n}-A y_{n}, j_{q}\left(v-b_{n}\right)\right\rangle \\
& -\left\langle\frac{b_{n}-y_{n}}{\lambda}, j_{q}\left(v-b_{n}\right)\right\rangle \\
\geq & \left\langle A b_{n}-A y_{n}, j_{q}\left(v-b_{n}\right)\right\rangle \\
& -\left\langle\frac{b_{n}-y_{n}}{\lambda}, j_{q}\left(v-b_{n}\right)\right\rangle,
\end{aligned}
$$

which implies $\left\langle w, j_{q}(v-z)\right\rangle \geq 0$ (letting $n \rightarrow \infty$ ).

Since $M$ is maximal accretive, we obtained that $z \in$ $M^{-1}(0)$, and, hence, $z \in \operatorname{VI}(K, A)$. This completes the proof.

The following corollaries follow from Theorem 17.

Corollary 18. Let $E=L_{p}$ space $(1<p<\infty)$. Let $K, P_{K}, \delta, A$, $r$, and $T_{i}, i=1,2, \ldots$ be as in Theorem 17. Let $\lambda \in(0,(2 \kappa /(p-$ $1))$ ), and define sequences $\left\{x_{n}\right\}$ and $\left\{y_{n}\right\}$ by (40). Then, $\left\{x_{n}\right\}$ and $\left\{y_{n}\right\}$ converge strongly to some element in $F$.

Corollary 19. Let $E=L_{p}$ space $(1<p<\infty)$. Let $K$, $P_{K}, \delta, A, r$, and $T_{i}, i=1,2, \ldots$ be as in Theorem 17. Let $\lambda \in(0,(2 \kappa /(p-1)))$, and define sequences $\left\{x_{n}\right\}$ and $\left\{y_{n}\right\}$ by (40). If for at least one in $\mathbb{N}, T_{i} P_{K}(I-\lambda A) T_{r}$ is demicompact, then the sequences $\left\{x_{n}\right\}$ and $\left\{y_{n}\right\}$ both converge strongly to some element in $F$.

Corollary 20. Let $E=H$ be a real Hilbert space. Let $K, P_{K}, \delta$, $A, r$, and $T_{i}, i=1,2, \ldots$ be as in Theorem 17. Let $\lambda \in(0,2 \kappa)$, and define sequences $\left\{x_{n}\right\}$ and $\left\{y_{n}\right\}$ by (40). Then, the sequences $\left\{x_{n}\right\}$ and $\left\{y_{n}\right\}$ both converge strongly to some element in $F$.

Remark 21. Prototypes of the sequences $\left\{\alpha_{n}\right\}$ and $\left\{\sigma_{i, n}\right\}$ in our theorems are the following:

$$
\alpha_{n}:=\frac{1}{n+1}, \quad \sigma_{i, n}:=\frac{n}{2^{i}(n+1)}, \quad \forall i \in \mathbb{N} .
$$

\section{References}

[1] R. C. James, "Orthogonality and linear functionals in normed linear spaces," Transactions of the American Mathematical Society, vol. 61, pp. 265-292, 1947.

[2] R. E. Bruck Jr., "Nonexpansive projections on subsets of Banach spaces," Pacific Journal of Mathematics, vol. 47, pp. 341-355, 1973.
[3] B. Ali, "Iterative approximation of common fixed points for families of nonexpansive mappings and solutions of variational inequalities," Advances in Nonlinear Variational Inequalities, vol. 12, no. 2, pp. 73-89, 2009.

[4] P.-E. Maingé, "Approximation methods for common fixed points of nonexpansive mappings in Hilbert spaces," Journal of Mathematical Analysis and Applications, vol. 325, no. 1, pp. 469479, 2007.

[5] P. Kumam and C. Jaiboon, "A new hybrid iterative method for mixed equilibrium problems and variational inequality problem for relaxed cocoercive mappings with application to optimization problems," Nonlinear Analysis: Hybrid Systems, vol. 3, no. 4, pp. 510-530, 2009.

[6] L. Ceng, S. Guu, and J. C. Yao, "Hybrid iterative method for finding common solutions of generalized mixed equilibrium and fixed point problems," Fixed Point Theory and Applications, vol. 2012, article 92, 2012.

[7] L.-C. Ceng and J.-C. Yao, "Strong convergence theorems for variational inequalities and fixed point problems of asymptotically strict pseudocontractive mappings in the intermediate sense," Acta Applicandae Mathematicae, vol. 115, no. 2, pp. 167191, 2011.

[8] L. C. Ceng, Q. H. Ansari, M. M. Wong, and J. C. Yao, "Mann type hybrid extragradient method for variational inequalities, variational inclusions and fixed point problems," Fixed Point Theory, vol. 13, pp. 403-422, 2012.

[9] P. L. Combettes and S. A. Hirstoaga, "Equilibrium programming in Hilbert spaces," Journal of Nonlinear and Convex Analysis, vol. 6, no. 1, pp. 117-136, 2005.

[10] H. He, S. Liu, and H. Zhou, "An explicit method for finding common solutions of variational inequalities and systems of equilibrium problems and fixed points of an infinite family of nonexpansive mappings," Nonlinear Analysis: Theory, Methods \& Applications, vol. 72, no. 6, pp. 3124-3135, 2010.

[11] P. Kumam and P. Katchang, "A viscosity of extragradient approximation method for finding equilibrium problems, variational inequalities and fixed point problems for nonexpansive mappings," Nonlinear Analysis: Hybrid Systems, vol. 3, no. 4, pp. 475-486, 2009.

[12] W. Kumam and P. Kumam, "Hybrid iterative scheme by a relaxed extragradient method for solutions of equilibrium problems and a general system of variational inequalities with application to optimization," Nonlinear Analysis: Hybrid Systems, vol. 3, no. 4, pp. 640-656, 2009.

[13] H. Y. Li and Y. F. Su, "Strong convergence theorem by a new hybrid method for equilibrium problems and variational inequality problems," Nonlinear Analysis: Theory, Methods \& Applications, vol. 72, no. 2, pp. 847-855, 2010.

[14] Z. Ma, L. Wang, and C. Hua, "Strong convergence of an iteration method for mixed equilibrium problems and common fixed point problems of a finite family of nonexpansive mappings in Hilbert spaces," International Mathematical Forum, vol. 6, no. 13-16, pp. 723-738, 2011.

[15] G. Marino, L. Muglia, and Y. Yao, "Viscosity methods for common solutions of equilibrium and variational inequality problems via multi-step iterative algorithms and common fixed points," Nonlinear Analysis: Theory, Methods \& Applications, vol. 75, no. 4, pp. 1787-1798, 2012.

[16] D. R. Sahu, N. C. Wong, and J. C. Yao, "A unified hybrid iterative method for solving variational inequalities involving generalized pseudocontractive mappings," SIAM Journal on Control and Optimization, vol. 50, no. 4, pp. 2335-2354, 2012. 
[17] K. Wattanawitoon, T. Jitpeera, and P. Kumam, "A new hybrid general iterative algorithm for common solutions of generalized mixed equilibrium problems and variational inclusions," Journal of Inequalities and Applications, vol. 2012, article 138, 2012.

[18] D. J. Wen and Y. Chen, "Generalized iterative methods for generalized equilibrium problems and fixed point problems of $k$-strict pseudo-contractions," Fixed Point Theory and Applications, vol. 2012, article 125, 2012.

[19] L.-C. Ceng, S.-M. Guu, H.-Y. Hu, and J.-C. Yao, "Hybrid shrinking projection method for a generalized equilibrium problem, a maximal monotone operator and a countable family of relatively nonexpansive mappings," Computers \& Mathematics with Applications, vol. 61, no. 9, pp. 2468-2479, 2011.

[20] W. Takahashi and K. Zembayashi, "Strong convergence theorem by a new hybrid method for equilibrium problems and relatively nonexpansive mappings," Fixed Point Theory and Applications, Article ID 528476, 11 pages, 2008.

[21] J. Chen, Y. J. Cho, and Z. Wan, "Shrinking projection algoriyhms for equilibrium problems with bifunction defined on the dual space of a Banach space," Fixed Point Theory and Applications, vol. 2011, article 92, 2011.

[22] W. Takahashi and K. Zembayashi, "Strong and weak convergence theorems for equilibrium problems and relatively nonexpansive mappings in Banach spaces," Nonlinear Analysis: Theory, Methods \& Applications, vol. 70, no. 1, pp. 45-57, 2009.

[23] H. Zegeye, E. U. Ofoedu, and N. Shahzad, "Convergence theorems for equilibrium problem, variational inequality problem and countably infinite relatively quasi-nonexpansive mappings," Applied Mathematics and Computation, vol. 216, no. 12, pp. 3439-3449, 2010.

[24] W. V. Petryshyn, "A characterization of strict convexity of Banach spaces and other uses of duality mappings," vol. 6, pp. 282-291, 1970.

[25] K. Goebel and W. A. Kirk, Topics in Metric Fixed Point Theory, vol. 28 of Cambridge Studies in Advanced Mathematics, Cambridge University Press, Cambridge, UK, 1990.

[26] T. Suzuki, “Strong convergence of Krasnoselskii and Mann's type sequences for one-parameter nonexpansive semigroups without Bochner integrals," Journal of Mathematical Analysis and Applications, vol. 305, no. 1, pp. 227-239, 2005.

[27] H.-K. Xu, "Iterative algorithms for nonlinear operators," Journal of the London Mathematical Society. Second Series, vol. 66, no. 1, pp. 240-256, 2002.

[28] H. K. Xu, "Inequalities in Banach spaces with applications," Nonlinear Analysis: Theory, Methods \& Applications, vol. 16, no. 12, pp. 1127-1138, 1991.

[29] S. Kamimura and W. Takahashi, "Strong convergence of a proximal-type algorithm in a Banach space," SIAM Journal on Optimization, vol. 13, no. 3, pp. 938-945, 2002.

[30] E. Blum and W. Oettli, "From optimization and variational inequalities to equilibrium problems," The Mathematics Student, vol. 63, no. 1-4, pp. 123-145, 1994. 


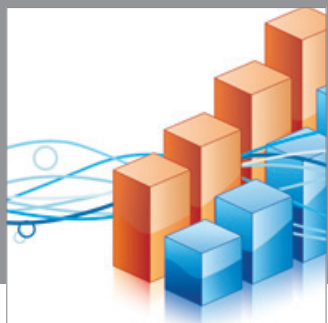

Advances in

Operations Research

mansans

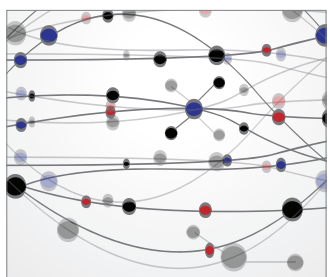

The Scientific World Journal
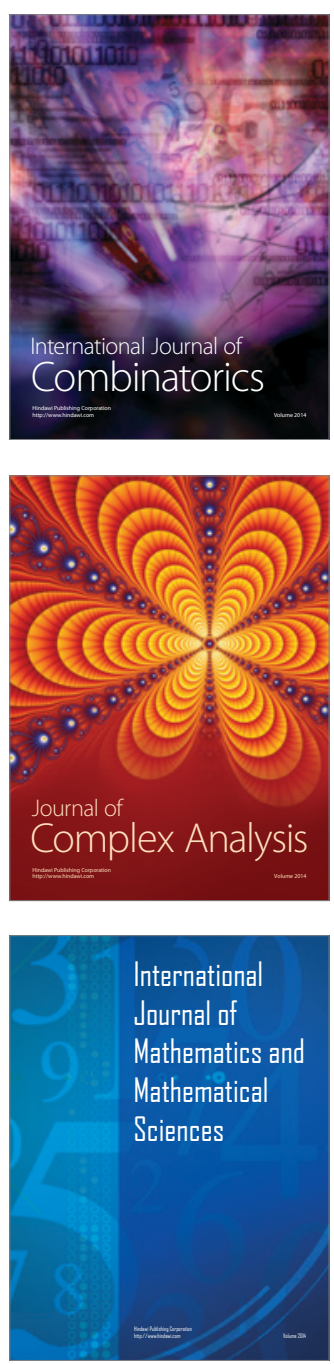
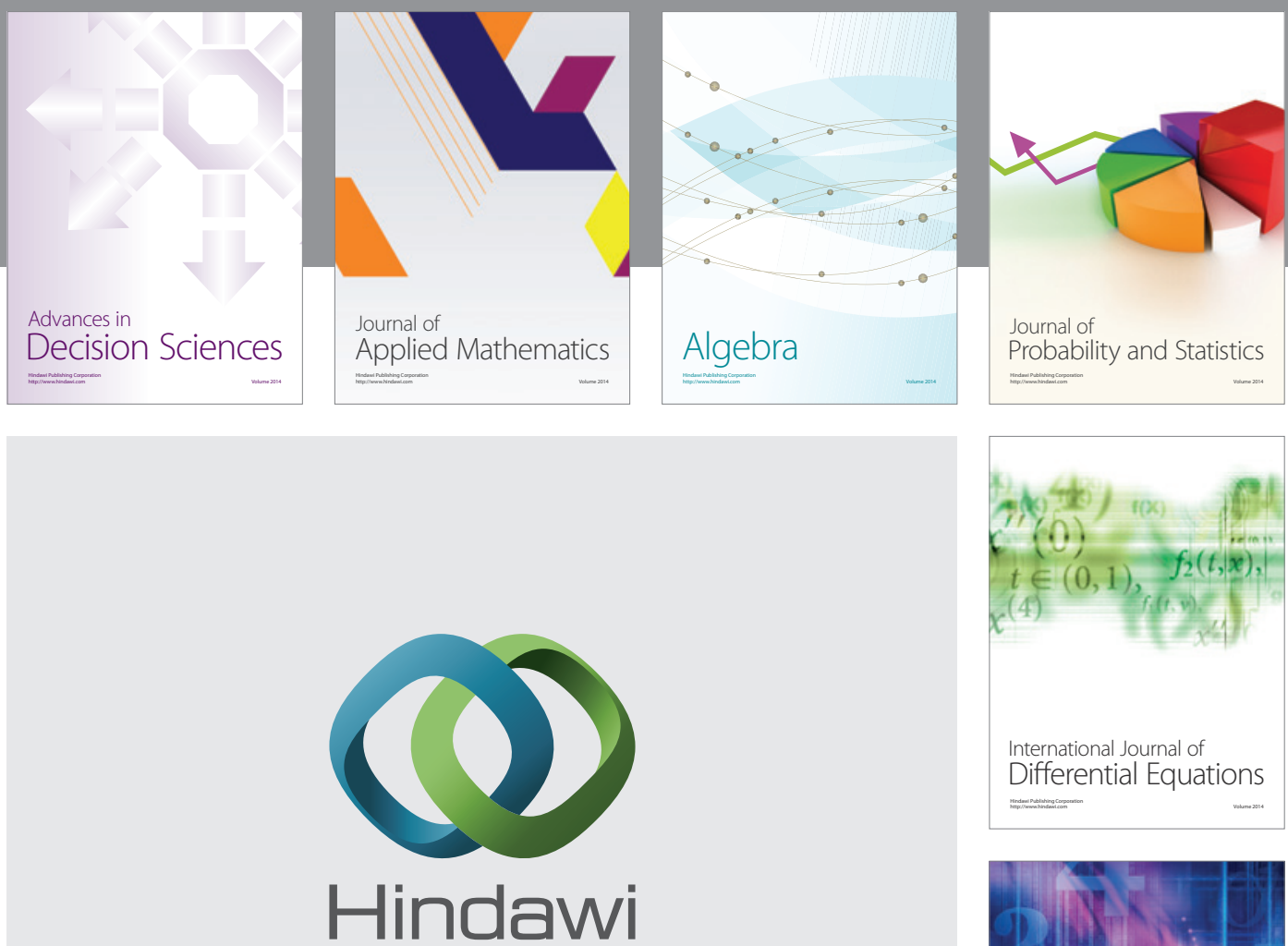

Submit your manuscripts at http://www.hindawi.com
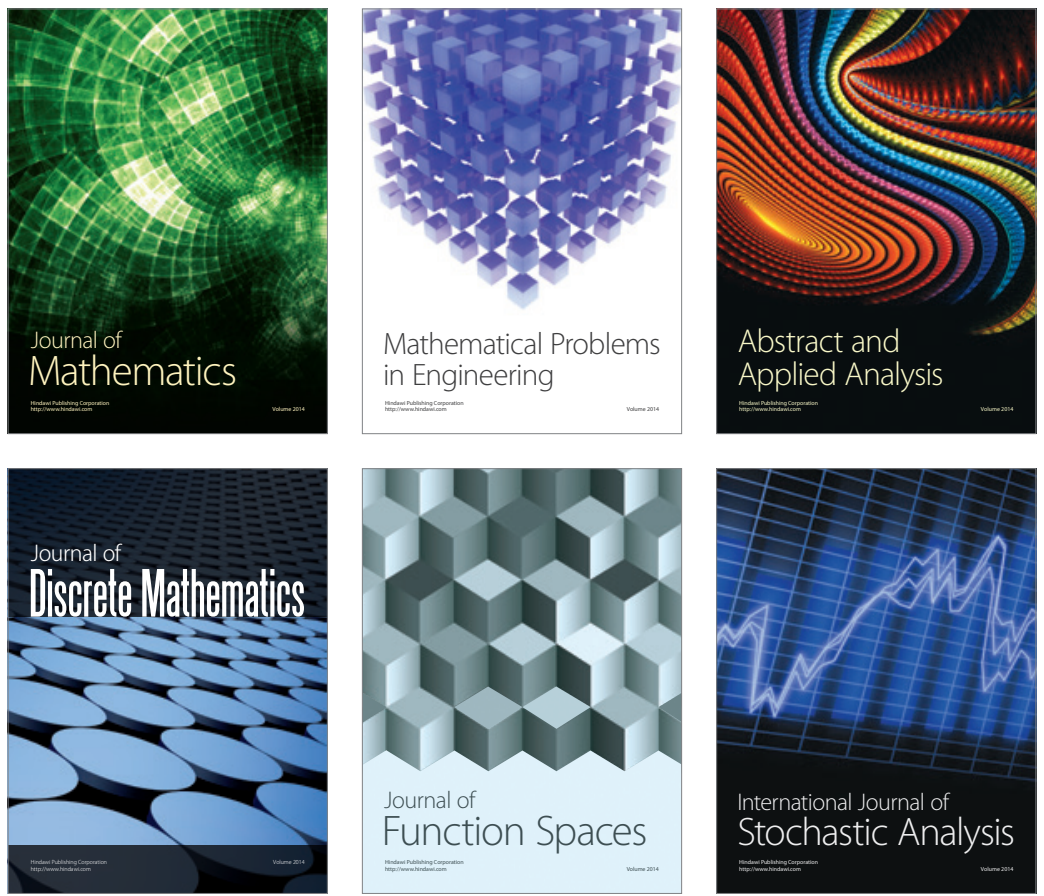

Journal of

Function Spaces

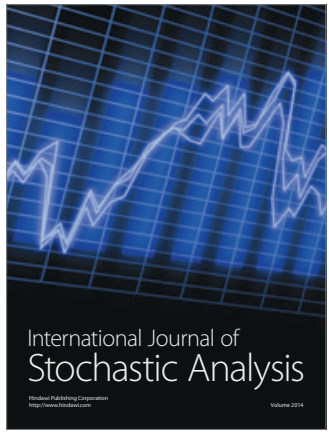

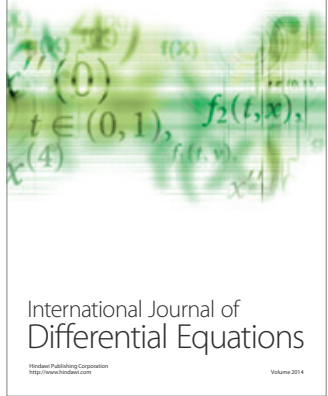
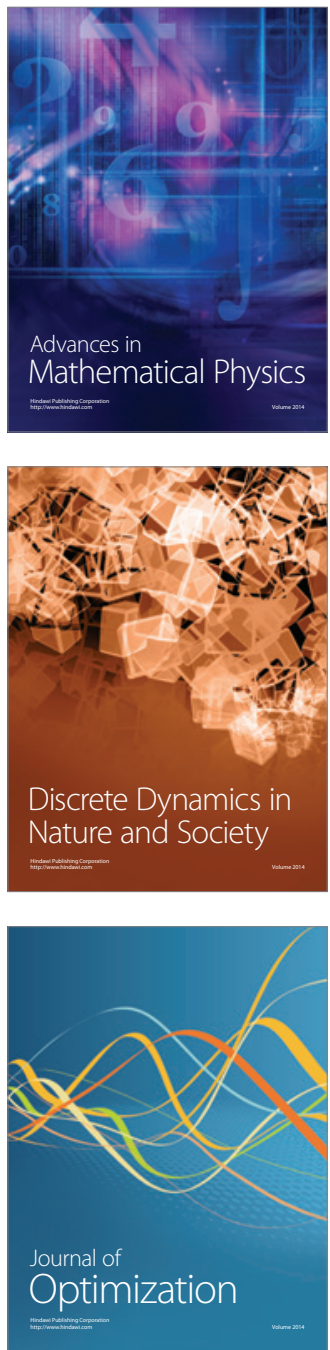